\title{
Somatic trinucleotide change encompassing codons 882 and 883 of the RET proto-oncogene in a patient with sporadic medullary thyroid carcinoma
}

\author{
Maria João Bugalho, Ibraim Coelho and Luís G Sobrinho \\ Department of Endocrinology/Laboratory of Molecular Biology, Portuguese Cancer Institute, 1093-Lisbon Codex, Portugal \\ (Correspondence should be addressed to Maria João Bugalho, Serviço de Endocrinologia, Instituto Português de Oncologia, 1093-Lisboa Codex, \\ Portugal; Email: bugal@mail.telepac.pt)
}

\begin{abstract}
Objective: Restriction analysis is a straightforward procedure for mutational analysis. It is commonly used for screening RET mutations. Incomplete digestion is a well-known cause of false results. Herein, we report another limitation of the method.

Design and Methods: Screening for somatic mutations in RET exons 16, 13 and 15 was performed in a patient with a sporadic medullary thyroid carcinoma. Genetic study was carried out by both restriction analysis and direct sequencing.

Results: A somatic trinucleotide change encompassing codons 882 and 883 of the RET proto-oncogene (GTA GCT to GTT TTT) was documented. Particular to this case is the silent mutation (GTA $\rightarrow$ GTT) at codon 882. Independently, both the novel silent mutation and the missense mutation at codon 883 may disrupt the same AluI restriction site. Based on the restriction pattern we were able to say that both mutations occurred in the same allele.

Conclusions: Restriction analysis is an easy approach for screening RET mutations; however, it is not enough to assign a final diagnosis.
\end{abstract}

European Journal of Endocrinology 142 573-575

\section{Introduction}

RET proto-oncogene localizes to $10 \mathrm{q} 11.2$ (1) and encodes a tyrosine receptor. Activating mutations affecting different domains of RET proto-oncogene are associated with multiple endocrine neoplasia types $2 \mathrm{~A}$ and 2B (MEN 2A and 2B) and with familial medullary thyroid carcinoma (FMTC) or sporadic medullary thyroid carcinoma (MTC). MEN 2 (OMIM no. 171400) and FMTC (OMIM no. 155240) are both autosomal dominant familial cancer syndromes. Although not frequently, mutations may occur within exon 15. Marsh et al. (2) described a somatic mutation at codon 883 in one of 32 sporadic tumors. Later, germline mutations were documented at codon 891 in FMTC patients (3) and at codon 883 in MEN 2B patients (4).

We here report the coexistence, in the same allele, of two somatic mutations affecting codons 882 and 883 of the RET proto-oncogene.

\section{Materials and methods}

The patient, a Caucasian male, was diagnosed and operated on at the age of 35 years. He is alive 3 years after surgery but has cervical and mediastinal lymph nodes as well as bone metastases.

PCR primers (5) were as follows: upstream (CRT 17B): GTC TCA CCA GGC CGC TAC and downstream (CRT 17G): ATG GTG CAC CTG GGA TCC CT. PCR conditions and analysis of PCR products were as follows: approximately $100 \mathrm{ng}$ genomic DNA were amplified in a $40 \mu \mathrm{l}$ reaction. Genomic DNA was denatured for $5 \mathrm{~min}$ at $95^{\circ} \mathrm{C}$ prior to 35 cycles of $94{ }^{\circ} \mathrm{C}, 64^{\circ} \mathrm{C}$ and $72{ }^{\circ} \mathrm{C}$ for $45 \mathrm{~s}$ at each temperature, followed by a $7 \mathrm{~min} 72^{\circ} \mathrm{C}$ polishing step. Amplified products were digested with AluI and separated electrophoretically on $10 \%$ polyacrylamide gels. The gels were stained with ethidium bromide and analysed under u.v. light. The purified PCR products were directly sequenced using Sequenase Version 2.0 kit (USB, Cleveland, OH, USA).

\section{Results}

After having excluded the presence of the most common germline mutations, the patient was screened for somatic mutations. Since the 883 somatic mutation destroys one restriction site for the AluI enzyme, exon 15 was initially screened by restriction analysis. As seen 


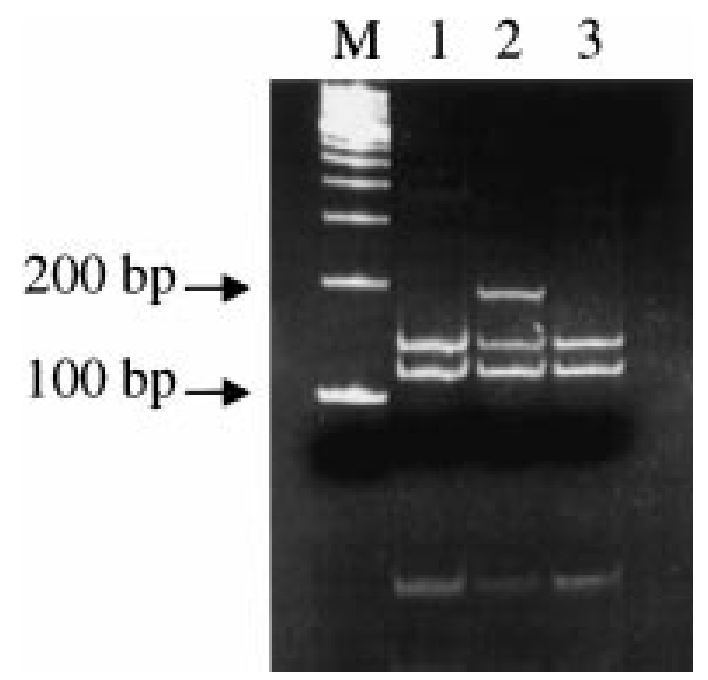

Figure 1 Ethidium bromide-stained polyacrylamide gel of Alul restriction digestion of RET exon 15 amplicons. Lane 1, negative control; lane 2, tumour DNA from patient; lane 3, corresponding germline DNA for tumour in lane 2. For the mutant allele, restriction digestion produces bands of 175 and $118 \mathrm{bp}$. For the normal allele, restriction digestion produces bands of 135,118 and $40 \mathrm{bp}$. M denotes the lane containing the 100 bp ladder marker (Gibco/BRL, Gaithersburg, MD, USA).

in Fig. 1, the restriction pattern suggested the presence of the A883F mutation.

Sequence analysis not only confirmed the expected mutation but also documented a second sequence alteration involving codon 882 (Fig. 2). This last event is a silent mutation, GTA $\rightarrow$ GTT $(\mathrm{Val} \rightarrow \mathrm{Val})$ which, by itself, also destroys the same restriction point for AluI. Since the restriction pattern corresponding to peripheral blood DNA was normal, as shown in lane 3 of Fig. 1, the second variant could not be interpreted as a polymorphism.

\section{Discussion}

No occult or de novo germline mutations in RET were found in this patient with an apparently sporadic MTC.

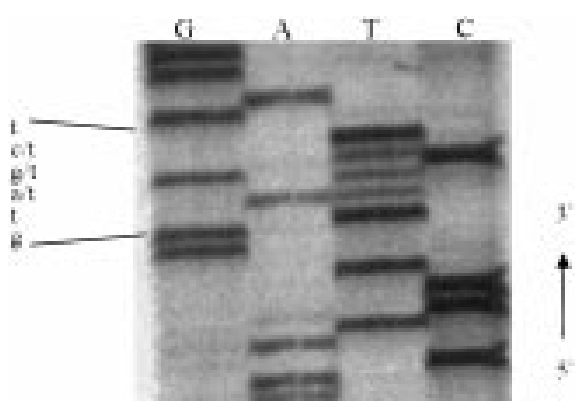

Figure 2 DNA sequence analysis of exon 15 PCR amplification products from tumour DNA. Heterozygosity at codon 882 $(\mathrm{GTA} \rightarrow \mathrm{GTT})$ and at codon 883 (GCT $\rightarrow$ TTT) can be observed.
The frequency of germline mutations, either inherited or de novo, in sporadic MTC patients depends on the series ranging from $1.5 \%$ to $6 \%(6,7)$.

Somatic mutations in RET have been described in $23-69 \%$ of sporadic MTCs. The most common occurs within codon $918(8,9)$. Mutations in codons 768 (10) and 883 (2) have been reported less frequently. In a few cases, MEN 2A-like somatic mutations $(11,12)$, as well as deletions in exons 10 and 11 , have been identified. Furthermore, sporadic MTCs may have different cell subpopulations, some of which carry somatic mutations while others do not or, alternatively, different subsets of cells can carry different somatic mutations (13).

In the present case, in addition to the previously described codon 883 mutation, we found a second sequence variant at codon $882(\mathrm{GTA} \rightarrow \mathrm{GTT})$ present in a heterozygous state. The $\mathrm{A} \rightarrow \mathrm{T}$ substitution, at the third position, disrupts one restriction site for AluI independently of the 883 mutation that also destroys the same restriction site. Moreover, based on the heterozygous AluI restriction pattern it is possible to say that both mutations occurred in the same allele (in cis). As a silent mutation, it can hardly be responsible for the aggressive behaviour of disease noticed in our patient. Nevertheless, it is necessary to be cautious in the interpretation of apparently neutral variants as these kinds of sequence variants can lead to an aberrantly spliced product $(14,15)$.

Most of the time, restriction analysis is an easy and reliable detection strategy for RET mutations. The present case points out one limitation of this method. Given the possible coexistence of different mutations associated with the same restriction pattern, only sequencing analysis will further clarify and definitely establish the diagnosis of exon 15 somatic mutations.

\section{References}

1 Ishizaka Y, Itoh F, Tahira T, Ikeda I, Sugimura T, Tucker J et al. Human ret proto-oncogene mapped to chromosome 10q11.2. Oncogene 19894 1519-1521.

2 Marsh DJ, Learoyd DL, Andrew SD, Krishnan L, Pojer R, Richardson A-L et al. Somatic mutations in the RET protooncogene in sporadic medullary thyroid carcinoma. Clinical Endocrinology 199644 249-257.

3 Hofstra RM, Fattoruso O, Quadro L, Wu Y, Libroia A, Verga U et al. A novel point mutation in the intracellular domain of the RET proto-oncogene in a family with medullary thyroid carcinoma. Journal of Clinical Endocrinology and Metabolism 199782 41764178.

4 Gimm O, Marsh DJ, Andrew SD, Frilling A, Dahia PLM, Mulligan LM et al. Germline dinucleotide mutation in codon 883 of the RET proto-oncogene in multiple endocrine neoplasia type 2B without codon 918 mutation. Journal of Clinical Endocrinology and Metabolism 199782 3902-3904.

5 Mulligan LM, Eng C, Attié T, Lyonnet S, Marsh DJ, Hyland VJ et al. Diverse phenotypes associated with exon 10 mutations of the RET proto-oncogene. Human Molecular Genetics 19943 2163-2167.

6 Eng C, Mulligan LM, Smith DP, Healey CS, Frilling A, Raue F et al. Low frequency of germline mutations in the RET proto-oncogene in patients with apparently sporadic medullary thyroid carcinoma. Clinical Endocrinology 199543 123-127. 
7 Wohllk N, Cote GJ, Bugalho MJ, Ordonez N, Evans DB, Goepfert H et al. Relevance of RET proto-oncogene mutations in sporadic medullary thyroid carcinoma. Journal of Clinical Endocrinology and Metabolism 199681 3740-3745.

8 Eng C, Smith DP, Mulligan LM, Nagai MA, Healey CS, Ponder MA et al. Point mutation within the tyrosine kinase domain of the RET proto-oncogene in multiple endocrine neoplasia type $2 \mathrm{~B}$ and related sporadic tumors. Human Molecular Genetics 19943 237-241.

9 Zedenius J, Wallin G, Hamberger B, Nordenskjöld M, Weber G \& Larsson C. Somatic and MEN $2 \mathrm{~A}$ de novo mutations identified in the RET proto-oncogene by screening of sporadic MTCs. Human Molecular Genetics 19943 1259-1262.

10 Eng C, Smith DP, Mulligan LM, Healey CS, Zvelebil M], Stonehouse T] et al. A novel point mutation in the tyrosine kinase domain of the RET proto-oncogene in sporadic medullary thyroid carcinoma and in a family with FMTC. Oncogene 199510 509-513.

11 Romei C, Elisei R, Pinchera A, Ceccherini I, Molinaro E, Mancusi F et al. Somatic mutations of the RET proto-oncogene in sporadic medullary thyroid carcinoma are not restricted to exon 16 and are associated with tumor recurrence. Journal of Clinical Endocrinology and Metabolism 199681 1619-1622.
12 Bugalho MJ, Frade JP, Rosa Santos J, Limbert E \& Sobrinho L. Molecular analysis of the RET proto-oncogene in patients with sporadic medullary thyroid carcinoma: a novel point mutation in the extracellular cysteine-rich domain. European Journal of Endocrinology 1997136 423-426.

13 Eng C, Mulligan LM, Healey CS, Houghton C, Frilling A, Raue F et al. Heterogeneous mutation of the RET proto-oncogene in subpopulations of medullary thyroid carcinoma. Cancer Research $1996562167-2170$.

14 Richard I \& Beckmann JS. How neutral are synonymous codon mutations? Nature Genetics 199510259.

15 Borrego S, Eng C, Sánchez B, Sáez ME, Navarro E \& Antiñolo G. Molecular analysis of the ret and GDNF genes in a family with multiple endocrine neoplasia type 2A and Hirschsprung disease. Journal of Clinical Endocrinology and Metabolism 199883 33613364.

Received 14 December 1999

Accepted 8 March 2000 